\title{
Effect of extrusion-cooking conditions on the pasting properties of extruded white and red bean seeds
}

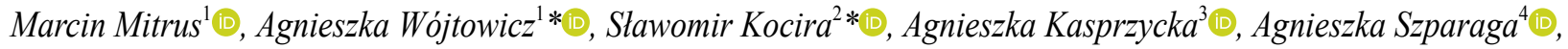 \\ Tomasz Oniszczuk ${ }^{1}$ (D) Maciej Combrzyński ${ }^{1}$ D,$K_{\text {Karol Kupryaniuk }}^{1}$, and Arkadiusz Matwijczuk ${ }^{5}$ (D) \\ ${ }^{1}$ Department of Thermal Technology and Food Process Engineering, University of Life Sciences in Lublin, Głęboka 31, \\ 20-612 Lublin, Poland \\ ${ }^{2}$ Department of Machinery Exploitation and Production Process Management, University of Life Sciences in Lublin, Głęboka 28, \\ 20-400 Lublin, Poland \\ ${ }^{3}$ Institute of Agrophysics, Polish Academy of Sciences, Doświadczalna 4, 20-290 Lublin, Poland \\ ${ }^{4}$ Department of Agrobiotechnology, Koszalin University of Technology, Racławicka 15-17, 75-620 Koszalin, Poland \\ ${ }^{5}$ Department of Physics, University of Life Sciences in Lublin, Akademicka 13, 20-950 Lublin, Poland
}

Received September 16, 2018; accepted June 5, 2019

\begin{abstract}
The extrusion-cooking technique may be used to convert the common bean into functional food products. There is still insufficient information on the properties of extruded beans. The aim of this work was to investigate the effect of extrusioncooking conditions on the pasting properties of two cultivars of the common bean (Aura and Toska) available on the Polish market. The bean was extruded using a twin-screw extruder at variable screws speeds and different amounts of water were added directly to the barrel. The pasting properties of the obtained extrudates were measured using a Micro Visco-Amylo-Graph. The extruded beans revealed more stable viscosity characteristics than the unprocessed ones. The addition of increased amounts of water to the processed material raised the peak viscosity of both extruded bean varieties. A higher screws speed during bean processing resulted in a higher peak viscosity only in the case of the Aura cultivar. However, the decreasing value of the cold paste viscosity was observed at higher speeds. This may indicate the negative effect of the extruder's screws speed on the gel formation ability of the extruded bean. The results showed that the extrusion-cooking process reduced the retrogradation tendency of bean paste due to starch degradation occurring during processing.

Keywords: common bean, extrusion-cooking, pasting properties
\end{abstract}

\section{INTRODUCTION}

Many legume and pulse cultivars (bean, pea, lentil) supply a large amount of protein to the human population (Bagherpour et al., 2010; Kocira et al., 2018a). Due to

*Corresponding author e-mail: agnieszka.wojtowicz@up.lublin.pl slawomir.kocira@up.lublin.pl a high content of starch, vitamins and minerals, protein and dietary fibre, pulses are a good source of nutrients, especially in countries where the consumption of animal protein is low (Blair, 2013; Berrios et al., 2010; Simmons et al., 2014; Siddiq et al., 2010; Wang and Ratnayake, 2014). The growing interest in the common bean (Phaseolus vulgaris L.) is connected with the rising number of consumers suffering from celiac disease. A diet with bean-based ingredients is an interesting alternative for people who cannot consume gluten. Additionally, legumes can reduce the risk of cardiovascular disease, diabetes, obesity, or colon cancer (Kutoš et al., 2003; Trinidad et al., 2010; Chung et al., 2008; Siddiq and Uebersax, 2013). Despite their nutritional and health benefits, the use of beans as a protein source is still limited in Europe due to a lack of knowledge concerning the functional characteristics of beans during processing (Kocira et al., 2018b; Piecyk et al., 2012).

Beans must not be eaten unprocessed (raw) as they contain trypsin inhibitors, tannins, saponins, and other anti-nutritional substances (Kiani Deh Kiani et al., 2008). For this reason, beans are processed before consumption. For example, soaking accelerates the cooking process and enhances the nutritional value and digestibility of beans (Rehman et al., 2001, Piecyk et al., 2012). Other wellknown bean treatments which improve their nutritional

(C) 2020 Institute of Agrophysics, Polish Academy of Sciences 
value and inhibit the activity of anti-nutritional substances in beans are fermentation, germination, roasting, and extrusion (Bouasla et al., 2017; Natabirwa et al., 2018).

The extrusion-cooking of food involves a quick conversion of starchy and protein-rich raw materials into a viscoelastic blend at a high temperature and pressure, this occurs in the presence of shear forces. This viscoelastic melt is plasticized and pushed forward by the extruder screw, or a pair of screws, and forced through a die. The abrupt drop in pressure outside the forming die causes the rapid evaporation of water as steam and the formation of the expanded structure of the final product (Mercier et al., 1989; Day and Swanson, 2013). The extrusion-cooking technique allows for the manufacture of a variety of foodstuffs, such as breakfast cereals, snacks and pellets, pasta, sweets, and many other food products (Bouasla et al., 2016; Mercier et al., 1989; Moscicki, 2011; Wójtowicz et al., 2017).

In recent years, the extrusion-cooking process has been used extensively in soy treatment and in the production of soy-based meat analogues (Guy, 2001). Recently, there has been an increased interest in the processing of legumes using this technique. This form of processing allows for the manufacture of products with the addition of legumes and ones made with legumes as the main ingredient, such as meat analogues, snacks or instant food components and additives (Osen et al., 2014; Rocha-Guzman et al., 2008; Ai et al., 2016; Siddiq et al., 2013). As yet, there is a lack of information concerning the properties of extrudates obtained from different bean varieties and their behaviour under varable extrusion-cooking conditions.

The aim of this work was to investigate the effect of extrusion-cooking parameters on the pasting properties of two cultivars of the common bean (Aura and Toska) available on the Polish market.

\section{MATERIALS AND METHODS}

Two common bean (Phaseolus vulgaris L.) cultivars were used in the experiment: the white Aura and red Toska. The moisture content of the bean seeds was approximately $8 \%$ d.m. The seeds were ground using a hammer mill equipped with a grid with $1 \mathrm{~mm}$ diameter openings.

The protein content was determined using the Kjeldahl method AACC 46-13.01, the fat content was determined using the AACC 30-25.01 method, the fibre content by the AACC 32-21.01 method and the ash content by the AACC 08-03.01 method (AACC, 2011). The total starch content was calculated based on the difference between the total weight of the sample $(100 \%)$ and the total protein, fat, fibre and ash contents. The chemical composition of the Aura bean seeds was as follows (in d.m.): protein $23.1 \%$, fibre $13.4 \%$, fat $1.2 \%$, ash $3.7 \%$, and starch $50.6 \%$, while the chemical composition of the Toska cultivar was the following: protein $24.3 \%$, fibre $17.9 \%$, fat $1.0 \%$, ash $4.6 \%$, and starch $44.2 \%$.
The ground beans were extruded separately using a twin-screw extruder (Evolum 25, Clextral, France) with a screw length/diameter ratio of $24: 1$. A die with a $5 \mathrm{~mm}$ diameter was used. The six temperature zones of the barrel were set at $50 / 80 / 100 / 120 / 130^{\circ} \mathrm{C}$ from the feeding to the die section. The extrusion-cooking treatment was performed at five different screws speeds: $300,400,500,600$ and $700 \mathrm{rpm}$. The raw materials were fed into the extruder by a screw feeder at a constant rate of $20 \mathrm{~kg} \mathrm{~h}^{-1}$. During extrusion-cooking, different amounts of water $(0.8,1.2$, 1.6, 2.0 and $2.4 \mathrm{l} \mathrm{h}^{-1}$ ) were added directly to the first barrel section. The extrudates were collected on meshed trays and cooled down to ambient temperature. After cooling, the bean extrudates were ground using a hammer mill in order to pass through a $0.8 \mathrm{~mm}$ sieve.

The pasting properties of extruded beans were determined using the Brabender Micro Visco-Amylo-Graph (Brabender, Germany) following the method described by Bouasla et al. (2016) and Wójtowicz et al. (2017). $10 \mathrm{~g}$ of the ground extrudate was dispersed in $100 \mathrm{~mL}$ of distilled water. Its pasting properties were evaluated at a constant speed $(250 \mathrm{rpm})$ and sensitivity $(235 \mathrm{cmg})$. Measurements were performed within the following profile: heating from 30 up to $93^{\circ} \mathrm{C}$ with a temperature gradient of $7.5^{\circ} \mathrm{C} \mathrm{min}^{-1}$, holding at $93^{\circ} \mathrm{C}$ for $5 \mathrm{~min}$, cooling from 93 to $50^{\circ} \mathrm{C}$ with a temperature gradient of $7.5^{\circ} \mathrm{C} \mathrm{min}^{-1}$, holding at $50^{\circ} \mathrm{C}$ for 1 min. Brabender Viscograph software (version 4.1.1) was used to determine the pasting properties. The following characteristics were evaluated: peak viscosity $(\mathrm{PV})$ - maximum viscosity recorded during the heating stage, hot paste viscosity (HPV) - paste viscosity after the 5 min holding at $93^{\circ} \mathrm{C}$ time period, cold paste viscosity $(\mathrm{CPV})$ - the viscosity achieved as the cooked paste was cooled down to $50^{\circ} \mathrm{C}$, breakdown (BD) - the difference between PV and HPV, setback (SB) - the difference between CPV and HPV.

A statistical analysis was conducted using Statistica software version 13.3 (StatSoft, USA). The results were evaluated using the ANOVA analysis of variance with a level of significance $\alpha=0.05$.

\section{RESULTS AND DISCUSSION}

Pasting characteristics are very important in the process of the selection of new food manufacturing additives such as, thickeners, emulsifiers, binders or other components which are related to paste viscosity (Natabirwa et al., 2018). The Micro Visco-Amylo-Graph is extremely useful in the evaluation and comparison of the pasting properties of raw and cooked starch and starchy products. Therefore, this equipment may be used for the indirect estimation of the intensity of the extrusion-cooking treatment of vegetable raw materials with a significant starch content. Examples of viscographs of unprocessed and extruded white bean are shown in Fig. 1. The pasting properties of non-treated beans showed similar profiles for both cultivars, with 


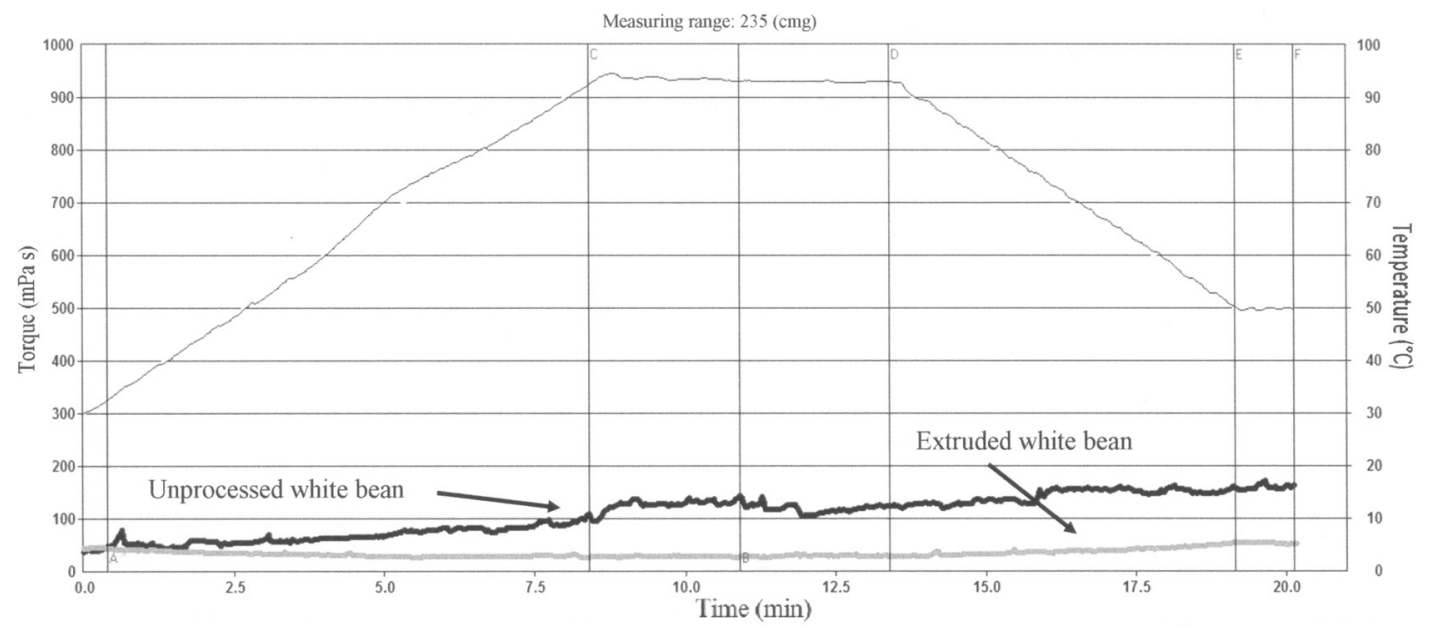

Fig. 1. Example of the viscographs of the unprocessed (black line) and extruded (grey line) Aura bean cultivar.

a greater paste viscosity at higher temperatures, this viscosity value did not decrease during the cooling stage. A similar behaviour was observed by Ai et al. (2016), Marquezi et al. (2016) and Natabirwa et al. (2018). Extruded beans showed more stable viscosity characteristics during measurements.

The changes in viscosity during the heating stage reflect the capacity of the material (mainly starch) to absorb water and swell. Thus, peak viscosity is influenced by many factors such as: starch granule swelling, amylose content, and starch leaching, as well as the presence of other components, such as proteins, lipids, and fibres (Lopes et al., 2012). Peak viscosity was difficult to detect in the pasting profiles of the raw and extruded bean. This behaviour may be attributed to the relatively low starch content and high protein content in the bean compared with other starchy materials. In the case of beans, starch granules may be surrounded by a protein matrix, which is related to the limited hydration and swelling capacity of starch granules (Ai et al., 2016). The top peak viscosity was observed for raw beans (149 $\mathrm{mPa}$ s for Aura and $125 \mathrm{mPa}$ s for Toska, respectively). Lower peak viscosity values were observed in extruded beans. Similar observations were reported by Siddiq et al. (2013) and Nkundabombi et al. (2016). The results of the parameters in question varied from 33 to $54 \mathrm{mPa} \mathrm{s}$ for the extruded Aura cultivar and from 51 to $66 \mathrm{mPa} \mathrm{s}$ for the extruded Toska cultivar. The addition of water to the barrel of the extruder during bean processing had a significant and positive effect on the increase in peak viscosity of both extruded bean cultivars (Tables 1 and 2). The adverse effect of screws speeds on peak viscosity was only observed in the case of the Toska bean (red variety) extruded with the highest water addition.

During the experiment, it was found that higher extruder's screws speeds caused a higher peak viscosity in the Aura cultivar (Fig. 2). In the case of the Toska cultivar, modified extruder screws speeds had a negligible effect on peak viscosity. Compared with unprocessed beans, the low- er peak viscosity values in extruded beans may be attributed to starch gelatinization and protein denaturation as well as to the interactions between starch and protein, which produces an extrudate structure with a low capacity for water absorption and swelling (Nkundabombi et al., 2016).

Hot paste viscosity (HPV) indicates the sensitivity of the swollen starch granules to shearing. During the holding period at $93^{\circ} \mathrm{C}$, swollen granules disintegrate due to the shearing of the paddle and rotating bowl, which results in a decreased viscosity known as viscosity breakdown. During the tests with unprocessed beans, the HPV values were $130 \mathrm{mPa}$ s for the Aura bean and $107 \mathrm{mPa}$ s for the Toska bean. The extruded beans were characterized by lower HPV values which ranged from 18 to $38 \mathrm{mPa}$ s for the white bean and from 27 to $59 \mathrm{mPa}$ s for the red bean (Fig. 3). The extrusion-cooking parameters showed a significant effect on the hot paste viscosity of the extruded beans: see Tables 1 and 2. The results showed that, regardless of the bean cultivar used, the increased water addition during the extrusion process results in an increase in the HPV value. A higher extruder's screws speed had a negative effect on the hot paste viscosity for both bean cultivars tested.

Cold paste viscosity (CPV), also known as the final viscosity, indicates a retrogradation tendency of the soluble amylose after cooling, or the ability of the starch paste to form a gel (Lopes et al., 2012). The extrusion-cooking parameters had a significant effect on the cold paste viscosity of the extruded beans (Tables 1 and 2). The results demonstrated that higher extruder's screws speeds caused a drop in the cold paste viscosity values. This effect was reported for both of the bean cultivars tested (Fig. 4). This may indicate the negative effect of the increased screws speed on the gel formation ability of the extruded bean paste due to high shear forces and, consequently, a more intensive treatment. The increase of water addition during bean processing had a positive effect on the CPV value and thus, on the gel formation ability of the bean extrudates. 
Table 1. Analysis of variance results of the influence of extrusion parameters on the pasting properties of the Aura cultivar

\begin{tabular}{|c|c|c|c|c|c|c|}
\hline $\begin{array}{l}\text { Pasting } \\
\text { properties }\end{array}$ & $\begin{array}{c}\text { Effect of } \\
\text { extrusion } \\
\text { parameters }\end{array}$ & Sum of squares & $\begin{array}{l}\text { Degrees of } \\
\text { freedom }\end{array}$ & Mean square & F-test & p-value \\
\hline \multirow{3}{*}{ PV } & SS & 809.4 & 4 & 202.3 & 23.97 & $<0.0001$ \\
\hline & WA & 191.8 & 4 & 47.9 & 5.68 & 0.0007 \\
\hline & SS $x$ WA & 1553.5 & 16 & 97.1 & 11.50 & $<0.0001$ \\
\hline \multirow{3}{*}{ HPV } & SS & 359.41 & 4 & 89.85 & 11.88 & $<0.0001$ \\
\hline & WA & 359.41 & 4 & 89.85 & 11.88 & $<0.0001$ \\
\hline & SS $x$ WA & 826.45 & 16 & 53.90 & 7.130 & $<0.0001$ \\
\hline \multirow{3}{*}{$\mathrm{CPV}$} & SS & 445.7 & 4 & 111.4 & 10.14 & $<0.0001$ \\
\hline & WA & 635.6 & 4 & 158.9 & 14.46 & $<0.0001$ \\
\hline & SS $x$ WA & 1901.3 & 16 & 118.8 & 10.82 & $<0.0001$ \\
\hline \multirow{3}{*}{$\mathrm{BD}$} & SS & 1556.08 & 4 & 389.02 & 37.12 & $<0.0001$ \\
\hline & WA & 583.01 & 4 & 145.75 & 13.91 & $<0.0001$ \\
\hline & SS x WA & 1063.25 & 16 & 66.45 & 6.34 & $<0.0001$ \\
\hline \multirow{3}{*}{ SB } & SS & 12.45 & 4 & 3.11 & 0.26 & 0.9046 \\
\hline & WA & 75.12 & 4 & 18.78 & 1.54 & 0.2037 \\
\hline & SS $x$ WA & 677.81 & 16 & 42.36 & 3.48 & 0.0004 \\
\hline
\end{tabular}

SS - screws speed, WA - water addition, PV - peak viscosity, HPV - hot paste viscosity, CPV - cold paste viscosity, BD - breakdown, $\mathrm{SB}$ - setback.

Table 2. Analysis of variance of the influence of extrusion-cooking parameters on the pasting properties of the Toska cultivar

\begin{tabular}{|c|c|c|c|c|c|c|}
\hline $\begin{array}{l}\text { Pasting } \\
\text { properties }\end{array}$ & $\begin{array}{c}\text { Effect of } \\
\text { extrusion } \\
\text { parameters }\end{array}$ & Sum of squares & $\begin{array}{l}\text { Degrees of } \\
\text { freedom }\end{array}$ & Mean square & F-test & p-value \\
\hline \multirow{3}{*}{ PV } & $\mathrm{SS}$ & 153.1 & 4 & 38.3 & 2.02 & 0.1057 \\
\hline & WA & 658.3 & 4 & 164.6 & 8.69 & $<0.0001$ \\
\hline & SS x WA & 860.7 & 16 & 53.8 & 2.84 & 0.0025 \\
\hline \multirow{3}{*}{$\mathrm{HPV}$} & SS & 1025.1 & 4 & 256.3 & 32.97 & $<0.0001$ \\
\hline & WA & 3769.3 & 4 & 942.3 & 121.22 & $<0.0001$ \\
\hline & SS $x$ WA & 1303.7 & 16 & 81.5 & 10.48 & $<0.0001$ \\
\hline \multirow{3}{*}{$\mathrm{CPV}$} & SS & 4884.7 & 4 & 1221.2 & 85.92 & $<0.0001$ \\
\hline & WA & 10536.2 & 4 & 2634.0 & 185.32 & $<0.0001$ \\
\hline & SS x WA & 3780.2 & 16 & 236.3 & 16.62 & $<0.0001$ \\
\hline \multirow{3}{*}{$\mathrm{BD}$} & SS & 1310.21 & 4 & 327.55 & 24.20 & $<0.0001$ \\
\hline & WA & 5502.08 & 4 & 1375.52 & 101.64 & $<0.0001$ \\
\hline & SS x WA & 1722.99 & 16 & 107.69 & 7.96 & $<0.0001$ \\
\hline \multirow{3}{*}{ SB } & SS & 1518.61 & 4 & 379.65 & 32.10 & $<0.0001$ \\
\hline & WA & 2148.61 & 4 & 537.15 & 45.42 & $<0.0001$ \\
\hline & SS x WA & 1418.59 & 16 & 88.66 & 7.50 & $<0.0001$ \\
\hline
\end{tabular}

Explanations as in Table 1. 
$\mathbf{a}$

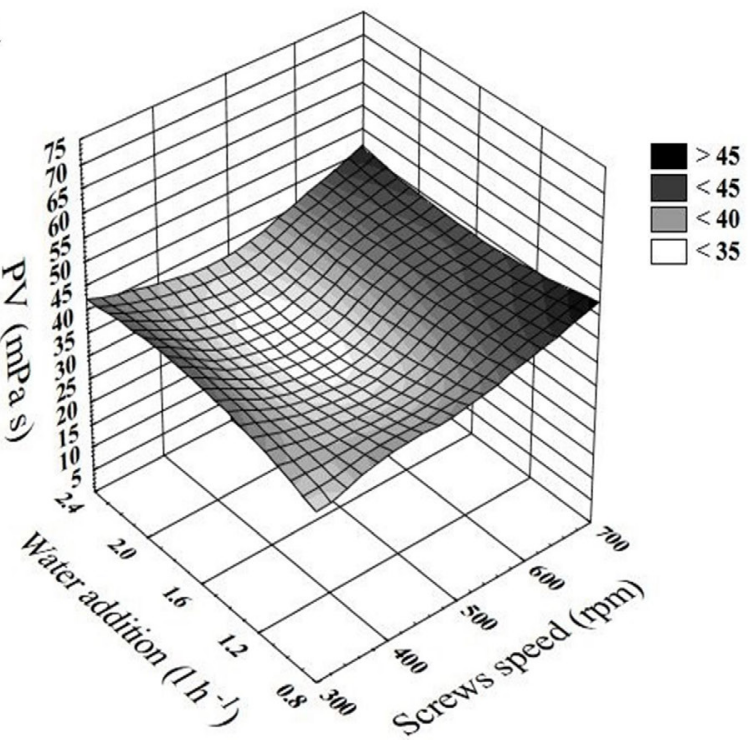

b

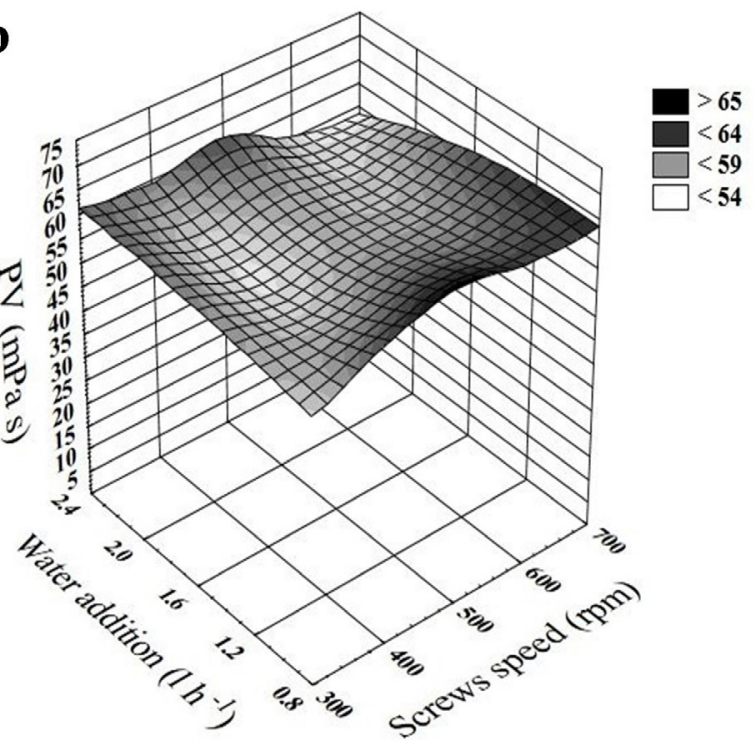

Fig. 2. Peak viscosity of the extruded beans: a) Aura (white) cultivar, b) Toska (red) cultivar.
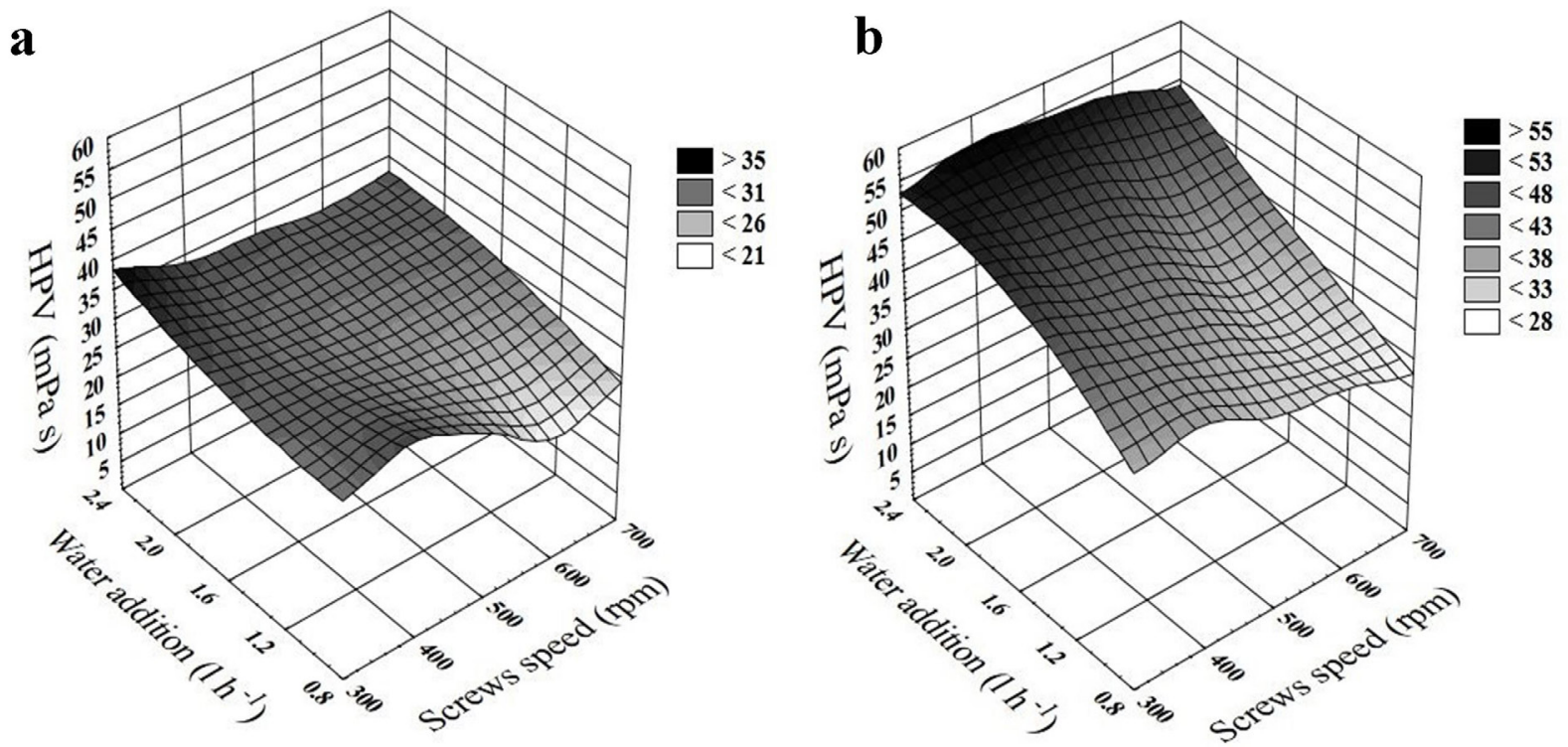

Fig. 3. Hot paste viscosity of the extruded beans: a) Aura (white) cultivar, b) Toska (red) cultivar.

However, this gel formation ability is much lower than that of the starchy extrudates (Mitrus et al., 2017) due to the high protein and fibre content and the interaction between the starch and other bean components (Marquezi et al., 2016). During the tests, it was found that the CPV values of the extruded beans ranged between 31-63 $\mathrm{mPa}$ s for Aura and 47-104 $\mathrm{mPa}$ s for Toska. These values were lower compared with the CPV values recorded for unprocessed beans (164 mPa s for Aura and $144 \mathrm{mPa}$ s for Toska). Similar findings have been reported by other researchers (Siddiq et al., 2013; Nkundabombi et al., 2016).
Breakdown (BD) is a characteristic feature of the susceptibility of cooked starch granules to disintegrate during continued stirring and heating. This is a demonstration of the stability of the paste during cooking. Higher extruder's screws speeds significantly increased the breakdown value. This effect was observed for both of the cultivars tested (Fig. 5). The addition of water during the extrusion-cooking of the Aura bean had an ambiguous effect on changes in the breakdown viscosity values. In the case of the Toska bean, increased water addition during extrusion showed a negative influence on the breakdown value. 
$\mathbf{a}$

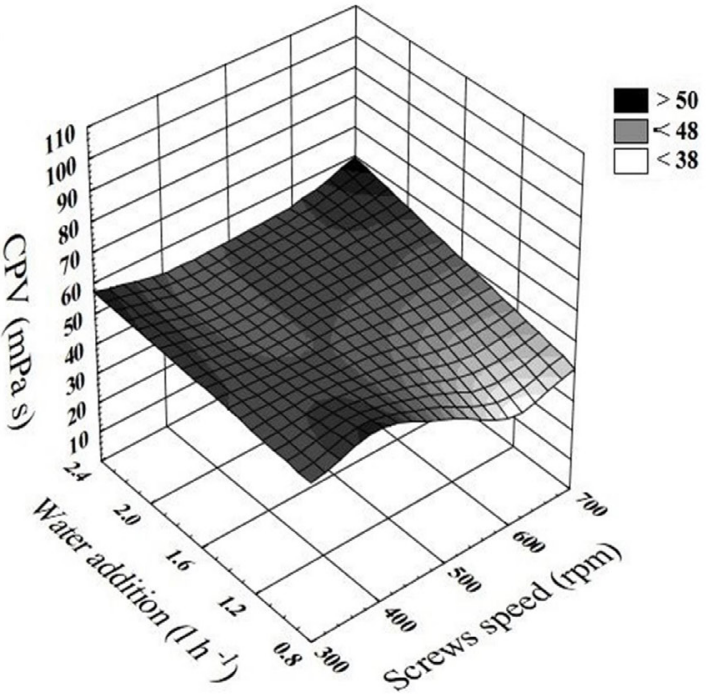

b

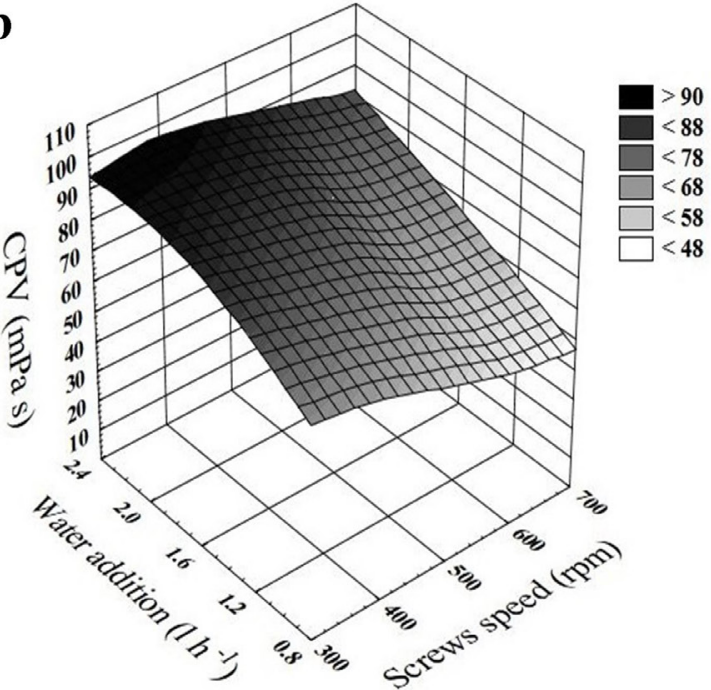

Fig. 4. Cold paste viscosity of the extruded beans: a) Aura (white) cultivar, b) Toska (red) cultivar.
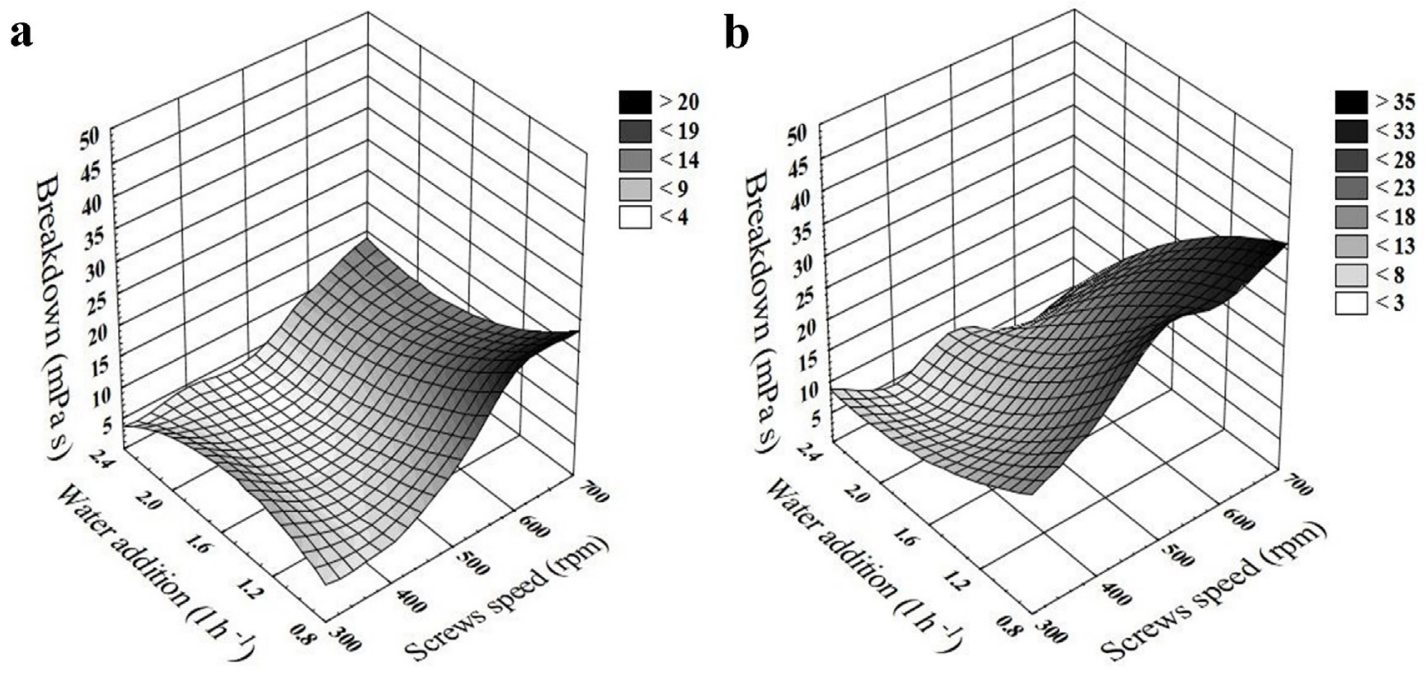

Fig. 5. Changes in the breakdown parameters of the extruded beans: a) Aura (white) cultivar, b) Toska (red) cultivar.

Setback (SB) reflects the retrogradation behaviour of starch gels. A higher setback value indicates a higher retrogradation tendency, and therefore further syneresis is likely to take place. The research results are presented in Fig. 6. The extruded beans were characterized by lower values of the setback parameter compared with the unprocessed ones. This suggests that extrusion-cooking reduces the retrogradation tendency of bean paste due to starch degradation occurring during processing (Nkundabombi et al., 2016). During the experiments, it was found that increased water addition during processing increased the setback value of the extruded Tosca cultivar. Pastes prepared from the Tosca bean extruded with higher screws speeds showed lower setback values. In the case of the Aura cultivar, no significant effects of the screws speed and water addition on the SB value were observed (Table 1).

\section{CONCLUSIONS}

1. The pasting properties of non-extruded beans showed a viscosity increase in tandem with a rising temperature from 30 up to $93^{\circ} \mathrm{C}$ but showed no decrease during the cooling stage. The extruded beans had the stable viscosity characteristics of a paste.

2. Increased water addition from 0.8 up to $2.41 \mathrm{~h}^{-1}$ during treatment had a positive effect on peak viscosity, this positive attribute was enhanced in comparison with non-extruded seeds. Increasing the speed of the extruder's screws from 300 up to $700 \mathrm{rpm}$ resulted in increased peak viscosity only in the case of the Aura cultivar. For the Tosca cultivar, the negligible effect of the screws speed on the PV value was observed. 

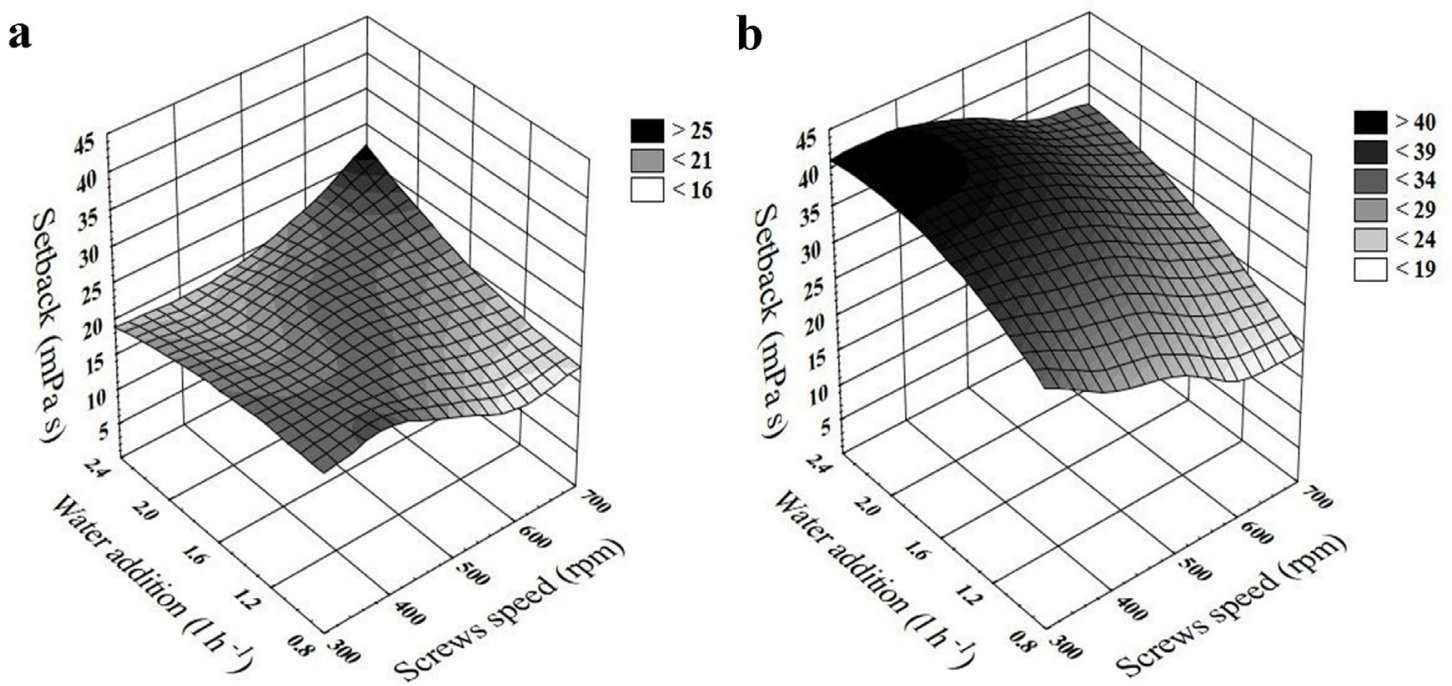

Fig. 6. Setback parameter changes of the extruded beans: a) Aura (white) cultivar, b) Toska (red) cultivar.

3. Regardless of the bean cultivar used, the increase in water addition from 0.8 up to $2.41 \mathrm{~h}^{-1}$ during extrusion-cooking treatment resulted in a higher HPV value. Increasing the speed of the extruder's screws from 300 up to $700 \mathrm{rpm}$ had a negative effect on the hot paste viscosity of both bean cultivars tested.

4. Increasing the screws speed from 300 up to $700 \mathrm{rpm}$ caused a decrease in the cold paste viscosity value. This may indicate the negative effect of the higher screws speed on gel formation of the extruded bean paste due to higher shear forces and more intensive treatment.

5. The gel formation ability of the extruded bean was lower compared to the unprocessed ones. The results suggest that extrusion-cooking reduced the retrogradation tendency of bean paste due to the degradation of starch during processing.

Conflict of interest: The Authors do not declare any conflict of interest.

\section{REFERENCES}

AACC International, 2011. Approved Methods of Analysis, 11th Ed., AACC International, St. Paul, MN, USA.

Ai Y., Cichy K.A., Harte J.B., Kelly J.D., and Ng P.K.W., 2016. Effect of extrusion cooking on the chemical composition and functional properties of dry common bean powders. Food Chem., 211, 538-545.

https://doi.org/10.1016/j.foodchem.2016.05.095

Bagherpour H., Minaei S., and Khoshtaghaza M.H., 2010. Selected physico-mechanical properties of lentil seed. Int. Agrophys., 24(1), 81-84.

Berrios J., De J., Morales P., Cámara M., and Sánchez-Mata M.C., 2010. Carbohydrate composition of raw and extruded pulse flours. Food Res. Int., 43, 531-536.

https://doi.org/10.1016/j.foodres.2009.09.035
Blair M.W., 2013. Mineral biofortification strategies for food staples: the example of common bean. J. Agric. Food Chem., 61, 8287-8294. https://doi.org/10.1021/jf400774y

Bouasla A., Wójtowicz A., and Zidoune M.N., 2017. Glutenfree precooked rice pasta enriched with legumes flours: physical properties, texture, sensory attributes and microstructure. LWT-Food Sci. Technol., 75, 569-577. https://doi.org/10.1016/j.lwt.2016.10.005

Bouasla A., Wójtowicz A., Zidoune M.N., Olech M., Nowak R., Mitrus M., and Oniszczuk A., 2016. Gluten-free precooked rice-yellow pea pasta: effect of extrusion-cooking conditions on phenolic acids composition, selected properties and microstructure. J. Food Sci., 81, C1070-C1079. https://doi.org/10.1111/1750-3841.13287

Chung H-J., Liu Q., Pauls K.P., Fan M.Z., and Yada R., 2008. In vitro starch digestibility, expected glycemic index and some physicochemical properties of starch and flour from common bean (Phaseolus vulgaris L.) varieties grown in Canada. Food Res. Int., 41, 869-875.

https://doi.org/10.1016/j.foodres.2008.03.013

Day L. and Swanson B.G., 2013. Functionality of protein-fortified extrudates. Compr. Rev. Food Sci. F., 12, 546-564. https://doi.org/10.1111/1541-4337.12023

Guy R., 2001. Extrusion Cooking: Technology and Application. CRC Press, Cambridge, England.

Kiani Deh Kiani M., Minaei S., Maghsoudi H., and Ghasemi Varnamkhasti M., 2008. Moisture dependent physical properties of red bean (Phaseolus vulgaris L.) grains. Int. Agrophysics, 22(3), 231-237.

Kocira S., Kocira A., Kornas R., Koszel M., Szmigielski M., Krajewska M., Szparaga A., and Krzysiak Z., 2018a. Effects of seaweed extract on yield and protein content of two common bean (Phaseolus vulgaris L.) cultivars. Legume Res., 41(4), 589-593. https://doi.org/10.18805/1r-383

Kocira S., Szparaga A., Kocira A., Czerwińska E., Depo K., Erlichowska B., and Deszcz E., 2018b. Effect of applying a biostimulant containing seaweed and amino acids on the content of fiber fractions in three soybean cultivars. Legume Res., https://doi.org/10.18805/lr-412 
Kutoš T., Golob T., Kač M., and Plestenjak A., 2003. Dietary fibre content of dry and processed beans. Food Chem., 80, 231-235. https://doi.org/10.1016/s0308-8146(02)00258-3

Lopes L.C.M., Batista K.A., Fernandes K.F., and Santiago R.A.C., 2012. Functional, biochemical and pasting properties of extruded bean (Phaseolus vulgaris L.) cotyledons. Int. J. Food Sci. Technol., 47, 1859-1865.

https://doi.org/10.1111/j.1365-2621.2012.03042.x

Marquezi M., Gervin V.M., Watanabe L.B., Bassinello P.Z., and Amante E.R., 2016. Physical and chemical properties of starch and flour from different common bean (Phaseolus vulgaris L.) cultivars. Brazilian J. Food Technol., 19. https://doi.org/10.1590/1981-6723.0516

Mercier C., Linko P., and Harper J.M., 1989. Extrusion Cooking. American Association of Cereal Chemists Inc., St. Paul, USA. https://doi.org/10.1002/star.19900420115

Mitrus M., Wójtowicz A., Oniszczuk T., Gondek E., and Mościcki L., 2017. Effect of processing conditions on microstructure and pasting properties of extrusion-cooked starches. Int. J. Food Eng., 13(6), https://doi.org/10.1515/ijfe-2016-0287

Moscicki L., 2011. Extrusion-Cooking Techniques. Application, Theory and Sustainability. Wiley-VCH, Weinheim, Germany.

Natabirwa H., Muyonga J.H., Nakimbugwa D., and Lungaho M., 2018. Physico-chemical properties and extrusion behaviour of selected common bean varieties. J. Sci. Food Agric., 98, 1492-1501. https://doi.org/10.1002/jsfa.8618

Nkundabombi M.G. Nakimbugwa D., and Muyonga J.H., 2016. Effect of processing methods on nutritional, sensory, and physicochemical characteristics of biofortified bean flour. Food Sci. Nutr., 4, 384-397. https://doi.org/10.1002/fsn3.301

Osen R., Toelstede S., Wild F., Eisner P., and Schweiggert-Weisz U., 2014. High moisture extrusion cooking of pea protein isolates: raw material characteristics, extruder responses, and texture properties. J. Food Eng., 127, 67-74. https://doi.org/10.1016/j.jfoodeng.2013.11.023

Piecyk M., Wołosiak R., Drużyńska B., and Worobiej E., 2012. Chemical composition and starch digestibility in flours from Polish processed legume seeds. Food Chem., 135, 10571064. https://doi.org/10.1016/j.foodchem.2012.05.051
Rehman Z., Salariya A.M., and Zafar S.I., 2001. Effect of processing on available carbohydrate content and starch digestibility of kidney beans (Phaseolus vulgaris L.). Food Chem., 73, 351-355. https://doi.org/10.1016/s0308-8146(00)00311-3

Rocha-Guzman N.E., Gallegos-Infante J.A., Gonzalez-Laredo R.F., Bello-Perez A., Delgado-Licon E., Ochoa-Martinez A., and Prado-Ortiz M.J., 2008. Physical properties of extruded products from three Mexican common beans (Phaseolus vulgaris L.) cultivars. Plant Food Hum. Nutr., 63, 99-104. https://doi.org/10.1007/s11130-008-0076-x

Siddiq M. and Uebersax M.A., 2013. Dry Beans and Pulses Production, Processing and Nutrition. Wiley-Blackwell, Iowa, USA. https://doi.org/10.1002/9781118448298

Siddiq M., Kelkar S., Harte J.B., Dolan K.D., and Nyombaire G., 2013. Functional properties of flour from low-temperature extruded navy and pinto beans (Phaseolus vulgaris L.). LWT-Food Sci. Technol., 50, 215-219. https://doi.org/10.1016/j.lwt.2012.05.024

Siddiq M., Ravi R., Harte J.B., and Dolan K.D., 2010. Physical and functional characteristics of selected dry bean (Phaseolus vulgaris L.) flours. LWT-Food Sci. Technol., 43, 232-237. https://doi.org/10.1016/j.lwt.2009.07.009

Simmons C.W., Hall III C., Tulbek M., Mendis M., Heck T., and Oguneyemi S., 2015. Acceptability and characterization of extruded pinto, navy and black beans. J. Sci. Food Agric., 95, 2287-2291. https://doi.org/10.1002/jsfa.6948

Trinidad T.P., Mallillin A.C., Loyola A.S., Sagum R.S., and Encabo R.R., 2010. The potential health benefits of legumes as a good source of dietary fibre. Br. J. Nutr., 103, 569574. https://doi.org/10.1017/s0007114509992157

Wang H. and Ratnayake W.S., 2014. Physicochemical and thermal properties of Phaseolus vulgaris L. var. Great Northern bean starch. J. Food Sci., 79, C295-C300. https://doi.org/10.1111/1750-3841.12357

Wójtowicz A., Oniszczuk A., Oniszczuk T., Kocira S., Wojtunik K., Mitrus M., Kocira A., Widelski J., and Skalicka-Woźniak K., 2017. Application of Moldavian dragonhead (Dracocephalum moldavica L.) leaves addition as a functional component of nutritionally valuable corn snacks. J. Food Sci. Technol., 54, 3218-3229. https://doi.org/10.1007/s13197-017-2765-7 